\title{
EFEITOS DE HERBICIDAS APLICADOS NO PERÍODO REPRODUTIVO SOBRE O CRESCIMENTO INICIAL DE PLANTAS DANINHAS NA GERAÇÃO SEGUINTE ${ }^{1}$
}

\author{
ANDRÉ ANDRES ${ }^{2}$ e NILSON G. FLECKS ${ }^{3}$
}

RESUMO

\begin{abstract}
Em 1990, 91 e 92 foi conduzido experimento na Faculdade de Agronomia da UFRS, em Porto Alegre, RS, com o objetivo de avaliar os efeitos de herbicidas aspergidos durante a fase reprodutiva em balãozinho (Cardiospermum halicacabum), corriola (Ipomoea grandifolia) e quinquilho (Datura stramonium). Foram testados dois compostos imidazolinonas (imazaquin e imazethapyr) e duas sulfoniluréias (chlorimuron e metsulfuron), e avaliadas as áreas foliar e cotiledonar, estatura e matéria seca das plântulas da geração seguinte. Em quinquilho, as áreas foliar e cotiledonar das plântulas aspergidas não diferiram da testemunha. Já as estaturas de balãozinho e quinquilho foram afetadas pelos her
\end{abstract}

bicidas: em quinquilho, especialmente por clorimuron; em balãozinho, além de clorimuron, também por metsulfuron. Diversos tratamentos afetaram a matéria seca total ou de segmentos de plântulas de quinquilho. Em corriola não se constataram efeitos dos tratamentos herbicidas nas variáveis avaliadas. De modo geral, as características de plântulas da geração seguinte foram afetadas por alguns herbicidas aplicados na fase reprodutiva, como matéria seca em quinquilho e estatura em balãozinho, dependendo do produto, dose e época de aplicação.

Palavras-chave: Características reprodutivas, imidazolinonas, sulfoniluréias, aplicações tardias.

\section{ABSTRACT \\ Effects of herbicides applied during reproductive period on initial growth of weed seedlings of the next generation}

A trial was conducted in 1990, 91 and 92 at Federal University of Rio Grande do Sul, in Porto Alegre, RS, Brazil, to investigate the effects of herbicides sprayed during the reproductive period of balloonvine (Cardiospermum halicacabum), morningglory (Ipomoea grandifolia), and jimsonweed (Datura stramonium). Two imidazolinones (imazaquin and imazethapyr) and two sulfonylureas (chlorimuron and metsulfuron) were tested and evaluated on foliar and cotyledonar areas, plant height, and dry matter of weed seedlings. In jimsonweed, foliar and cotyledonar areas of seedlings did not differ from the control. However, the heights of ballonvine and jimsonweed seedlings were affected by the herbicides: in jimsonweed specially by chlorimuron, in baloonvine by chlorimuron, and metsulfuron. Multiple treatment influenced total plant dry matter and also dry matter of some components of jimsonweed plants. In morningglory no effects of herbicide treatment on the traits evaluated were observed. In general, characteristics of seedlings of the next generation were influenced by some herbicides applied during the reproductive period of the mother plants, for example dry matter in jimsonweed and height in baloonvine, depending on the compound and rate used and its time of application.

Additional index words: Reproductive characteristics, imidazolinones, sulfonylureas, late applications, seedlings.

\footnotetext{
${ }^{1}$ Recebido para publicação em 04/0 1/94 e na forma revisado em 13/08/94. Extraído da dissertação do pri meiro autor para obtenção do grau de Mestre em Fitotecnia pela Faculdade de Agronomia da UFRS. Parcialmente financiado pelo CNPq.

${ }^{2}$ Eng $^{\circ}$ Agr $^{\circ}$, Aluno do Programa de Pós-Graduação em Agronomia. Faculdade de Agronomia, UFRS, Caixa Postal 776, Porto Alegre, RS $90001-970$

${ }^{3} \mathrm{Eng}^{\circ} \mathrm{Agr}^{\circ}$, PhD, Prof. Adjunto, Bolsista do CNPq, Dep. de Plantas de Lavoura, Faculd ade de Agronomia, UFR S, Caixa Posta1 776, Porto Alegre, RS 90001-970
} 


\section{INTRODUÇÃO}

As sementes de plantas daninhas nos solos agrícolas constituem o principal problema das infestações ocorrentes em função de persistirem por periodos variáveis. Sabe-se que pouco pode ser feito com relação à população de sementes dormentes no solo. Dessa forma, pesquisas com intuito de eliminar não apenas a viabilidade das sementes, mas também de atingir o desenvolvimento das futuras plântulas como método de prevenção, não tem atualmente merecido a devida importância. Esta abordagem, entretanto, pode trazer resultados promissores no futuro, como formação de plântulas débeis ou anormais na geração seguinte.

Devido à constatação em vários outros países da ocorrência crescente de espécies de plantas daninhas resistentes aos herbicidas, verifica-se que o incremento do banco de sementes provavelmente poderá ser maior no decorrer dos anos (Fenton \& Jutsun, 1991). Os herbicidas podem não só influenciar a dormência das sementes em formação (RojasGarciduenas \& Kommedahl, 1960), como também limitar o crescimento das plântulas por ocasião da germinação (Andersen \& Helgeson, 1958; Isaacs et al., 1989). Dalapon, aspergido em Avena fama no pleno afilhamento, atrasou em 7 dias a emergência das plântulas provenientes das sementes tratadas. Além disso, foram observados danos após a emergência da aveia, permanecendo as deformações nas plantas adultas, enquanto algumas plântulas não se desenvolveram além do estádio de coleóptilo (Andersen \& Helgeson, 1958).

Em Cyperus esculentus, o herbicida amitrole, aplicado em fases reprodutivas, foi detectado nas sementes em análise de laboratório através da autoradiografia com carbono marcado, indicando que pode ter ocorrido a translocação do produto do ponto de absorção para as sementes, tendo afetado sua germinação (Hill et a!., 1963). A gramínea Elymus caput-medusae, também tratada com amitrole nos estádios de emborrachamento e enchimento de grãos, apresentou reduções de 75 e $100 \%$, respectivamente, na viabilidade das cariopses. O mesmo ocorreu com aplicações de hidrazida maleica e dalapon. Todos os herbicidas afetaram posteriormente o desenvolvimento das plântulas (Evans et a!., 1963).

Os grupos químicos das imidazolinonas e das sulfoniluréias, devido sua rápida translocação e acúmulo em tecidos meristemáticos (Beyer et al., 1988; Claus, 1987; Congleton et a!., 1987; Ray, 1984; Shaner et a!., 1984), possuem potencial para manejos que envolvem aplicações em plantas adultas com vistas ao acúmulo em sementes, de modo a causar danos na geração seguinte.

As plantas daninhas Cardiospermum halicacabum (balãozinho); Datura stramonium (quinquilho) e Ipomoea aristolochiaefolia (corriola), devido às suas caracteristicas biológicas, possuem grande agressividade quando infestantes de áreas agricolas (Lorenzi, 1991), causando redução significativa na produção das culturas (Henry \& Bauman, 1991; Johnston et al., 1979; Mitich, 1989).

Devido à alta prolificidade das plantas daninhas (Carmona, 1992; Isaacs et al., 1989; Levitt \& Lovett, 1984; Weaver \& Warwick, 1984), à dormência das suas sementes (Carmona, 1992; Pawlak et al.,1990; Tay lorson, 1989; Weaver \& Warwick, 1984) e ao surgimento de resistência a certos herbicidas em diversas espécies (Fenton \& Jutsun,
1991), é indispensável a investigação de novas tecnologias que visem a impedir a sua reprodução, bem como afetar de forma ne \% tiva o desenvolvimento das novas plântulas.

Este trabalho tem como objetivo investigar os efeitos de herbicidas aplicados na fase reprodutiva de três espécies daninhas sobre o desenvolvimento inicial das plântulas da geração seguinte.

\section{MATERIAL E MÉTODOS}

O experimento foi conduzido, parte em casa-de-vegetação e parte em laboratório, no Departamento de Plantas de Lavoura da Universidade Federal do Rio Grande do Sul, em Porto Alegre, RS, e também no Laboratório de Análise e Tecnologia de Sementes do Instituto de Pesquisas Agronômicas (IPAGRO), da Secretaria da Agricultura e Abastecimento do Rio Grande do Sul.

Previamente, em campo, foram realizadas aplicações de herbicidas sobre plantas individuais (uma por tratamento), assim que a espécie alcançou o estádio desejado. Em quinquilho, estes estádios ocorreram quando as plantas apresentavam aproximadamente $60 \%$ de flores abertas em relação ao total dos botões florais e durante o enchimento de grãos, quando cerca de $70 \%$ dos frutos da planta apresentavam tamanho superior a $1 \mathrm{~cm}$ da base ao ápice. Nas demais espécies considerourse fase de floração quando mais de $50 \%$ das flores estavam abertas, e enchimento de grãos quando não havia mais flores na planta e, conseqü entemente, os frutos estavam em formação. As plantas aspergidas no primeiro estádio não foram tratadas no segundo e vice-versa. As plantas testemunhas não receberam aspersão.

A aplicação dos herbicidas (Tabela 1) foi realizada com auxílio de pulverizador costal de precisão, munido de bico de jato plano (leque), especificação 8002, operando à pressão de $150 \mathrm{kPa}$, e utilizando volume de calda correspondente a $500 \mathrm{I} / \mathrm{ha}$.

Empregou-se o delineamento experimental inteiramente casualizado, com quatro repetições, nos ensaios em campo, em casa-de-vegetação e em laboratório.

Após a coleta dos frutos e separação das sementes, estas foram acondicionadas em sacos de papel e conservadas em temperatura próxima de $0^{\circ} \mathrm{C}$, durante 45 dias (intervalo entre início e final da coleta). Cinqüenta sementes oriundas de plantas-mãe previamente tratadas foram semeadas em vasos plásticos contendo $500 \mathrm{~g}$ de solo peneirado e mantidos em condições de casa-de-vegetação. As plântulas emergidas (após desbaste mantendo-se cinco plântulas por vaso), com quatro folhas definitivas em quinquilho e balãozinho e três folhas definitivas em corriola, foram submetidas em laboratório às avaliações de estatura, matéria seca parcial e total, e também áreas cotiledonar e foliar. As áre as cotiledonar e foliar foram obtidas mediante equipamento eletrônico que as integrava através de varredura ótica (marca LICOR-LI 300). Para avaliara matéria seca de quinquilho, o material da parte aérea foi dividido em caule, folhas e cotilédones e, posteriormente, foram somadas as partes para obtenção da matéria seca total da parte aérea. No caso do balãozinho a parte aérea não foi dividida. A parte aérea de corriola foi separada em caule e folhas, e obtida a matéria seca total através da soma 
TABELA 1 - Herbicidas, grupos químicos e doses utilizados no experimento de campo. Porto Alegre, RS, 1990/91.

\begin{tabular}{|c|c|c|c|c|c|c|}
\hline \multirow[b]{2}{*}{ Metsulfuron } & \multirow{2}{*}{$\begin{array}{l}\text { Grupo químico } \\
\text { Sulfoniluréia }\end{array}$} & \multirow{2}{*}{$\begin{array}{c}\begin{array}{c}\text { Formulação e } \\
\text { concentração }\end{array} \\
\mathrm{GD}^{\mathrm{c}}, 600 \mathrm{~g} / \mathrm{kg}\end{array}$} & \multicolumn{2}{|c|}{ Doses $^{\mathrm{b}}(\mathrm{g} / \mathrm{ha})$} & \multicolumn{2}{|c|}{$\begin{array}{l}\text { Adjuvante e } \\
\text { concentraçáo }\end{array}$} \\
\hline & & & 2,4 & 1,2 & - & - \\
\hline Chlorimuron & Sulfoniluréia & $\mathrm{GD}, 250 \mathrm{~g} / \mathrm{kg}$ & 60 & 30 & - & - \\
\hline Imazaquin & Imidazolinona & $\mathrm{SA}^{\mathrm{d}}, 100 \mathrm{~g} / \mathrm{l}$ & 100 & 50 & Renex & $0,5 \% \mathrm{v} / \mathrm{v}$ \\
\hline Imazethapyr & Imidazolinona & $\mathrm{SA}, 150 \mathrm{~g} / \mathrm{l}$ & 150 & 75 & Renex & $0,5 \% \mathrm{v} / \mathrm{v}$ \\
\hline
\end{tabular}

anes comerciais: Ally, Classic, Scepter e Pivot, respectivaamente.

b Equivalentes à usual $\mathrm{e}$ à metade desta.

- $\mathrm{GD}=\mathrm{Grânulos} \mathrm{dispersíveis} \mathrm{em} \mathrm{água.}$

¿ $\mathrm{SA}=$ Solução aquosa.

dos segmentos. Em seqüência, o material foi submetido a secagem em estufa com circulação de ar à temperatura de $65^{\circ} \mathrm{C}$ durante quatro dias. Depois foi efetuada a pesagem do material seco das plântulas, obtendo-se o peso individual da parte aérea ou de seus segmentos.

As variáveis obtidas no experimento foram submetidas a dois tipos de análise de variância. A primeira envolveu delineamento constituído pelos quatro herbicidas, duas doses e duas épocas de aplicação, sem a inclusão da testemunha. Procedida a verificação da significância estatística, efetuouse a comparação das médias através do teste de Duncan, ao nível de $1 \%$ de probabilidade. Por esta análise foi possível comparar herbicidas, épocas de aplicação e doses de herbicidas, e também as respectivas interações entre estes fatores. Considerando o nível de significância empregado (1\%), as interações, na sua maioria, não foram significativas e pouco contribuíram para esclarecer os resultados sob ponto de vista biológico, sendo por isso desconsideradas. Na segunda análise de variância foi incluída a testemunha, realizando-se o teste " $t$ " de contrastes para detectar a significância entre os tratamentos e a testemunha. Posteriormente, fez-se necessário aplicar o teste bilateral de Dunnett ao nível de $1 \%$ de probabilidade para diferenciar cada tratamento herbicida da testemunha. Dessa forma, foram realizadas duas análises, uma vez que a primeira comparou apenas tratamentos envolvendo herbicidas, enquanto a segunda comparou a testemunha com cada tratamento herbicida.

\section{RESULTADOS E DISCUSSÃO}

As respostas das plantas daninhas aos herbicidas aplicados na fase reprodutiva ainda não estão completamente elucidadas. Em geral, tais efeitos podem refletir-se nas fases iniciais de desenvolvimento das novas plântulas originadas, afetando estatura, área foliar ou matéria seca de seus segmentos aéreos.

A área foliar, cotiledonar e estatura das plântulas de quinquilho não sofreram variação devido à aspersão dos herbicidas sobre as plantas-mãe durante a fase reprodutiva, em relação às plântulas-testemunha. $\mathrm{Na}$ comparação entre os fatores avaliados para área foliar e cotiledonar, como herbicidas, doses e épocas de aplicação, igualmente não foram constatadas diferenças entre os tratamentos (Tabela 2). Porém, com relação à estatura das plântulas de quinquilho, chlorimuron mostrou-se mais eficiente que metsulfuron em reduzir esta variável, enquanto imazaquin e imazethapyr permaneceram em posição intermediária (Tabela 2).

Diversos tratamentos afetaram a matéria seca total ou de partes das plântulas de quinquilho (Tabela 3). Quanto ao segmento folhas, chlorimuron a meia-dose, no florescimento e no enchimento de grãos, e imazethapyr, em ambas as doses no florescimento, reduziram-no em 32, 37, 28 e $26 \%$, respectivamente, em relação à testemunha. $\mathrm{O}$ componente caule foi afetado apenas pela meia-dose de chlorimuron aplicado no enchimento de grãos (redução de $42 \%$ ). 0 peso total da matéria seca da parte aérea de plântulas-testemunha de quinquilho foi 35 e $38 \%$ superior, respectivamente, ao de metsulfuron na dose-plena aplicada no florescimento e ao da meiadose aplicada por ocasião do enchimento de grãos. Chlorimuron, em ambas as doses, aplicado no florescimento, e a meia-dose no enchimento de grãos, reduziu esta variável em 32,24 e $36 \%$, respectivamente, em relação à testemunha. O peso da matéria seca dos cotilédones de plântulas-testemunha de quinquilho não diferiu daqueles encontrados nas plântulas oriundas de plantas-mãe aspergidas pelos tratamentos herbicidas (Tabela 3 ).

No caso dos compostos imidazolinonas, os tratamentos que incluíram imazaquin em dose-plena e imazethapyr nas duas doses, aplicados no florescimento, reduziram o conteúdo total de matéria seca da parte aérea de plântulas de quinquilho em 25,24 e $27 \%$, respectivamente, em relação à testemunha (Tabela 3). Tanto a matéria seca da parte aérea de plântulas de quinquilho, como o peso dos segmentos folhas, cotilédones e caule não mostraram comportamento diferenciado quanto aos efeitos isolados de compostos, doses e épocas de aplicação.

A expectativa deste modelo de ação é de que, em função das características particulares dos grupos herbicidas envolvidos e devido a sua pronta translocação e acúmulo em tecidos meristemátic os (Beyer, et al., 1988; Ray, 1984; Shaner, et al., 1984), eles sejam carreados junto com produtos assimilados de vários órgãos, após a antese, com a finalidade de incrementar o peso das sementes. Esta remobilização poderia, além de incrementar o peso das sementes, acelerar a morte das plantas por ação dos herbicidas acumulados. Além disso, em decorrência desta translocação de reservas para órgãos em franco desenvolvimento, poderá ocorrer acúmulo de moléculas nas sementes. Contudo, se os herbicidas aceleram a morte ou maturação das plantas, 
TABELA 2 - Áreas foliar e cotiledonar e estatura de plântulas de Datura stramonium oriundas de plantas-mãe aspergidas com herbicidas na fase reprodutiva. Porto Alegre, RS, 1991/92.

\begin{tabular}{|c|c|c|c|}
\hline \multirow{2}{*}{$\begin{array}{c}\text { Tratamentos } \\
\text { Fatores e níveis }\end{array}$} & \multicolumn{3}{|c|}{ Características } \\
\hline & $\begin{array}{c}\text { Área foliar } \\
\left(\mathrm{cm}^{2} / \text { plântula }\right)\end{array}$ & $\begin{array}{l}\text { Área cotiledonar } \\
\left(\mathrm{cm}^{2} / \text { plântula }\right)\end{array}$ & $\begin{array}{c}\text { Estatura } \\
\text { (cm/plântula) }\end{array}$ \\
\hline \multicolumn{4}{|l|}{ Herbicidas } \\
\hline Imazaquin & $22,5 \mathrm{a}^{*}$ & $2,28 \mathrm{a}$ & $6,72 \mathrm{ab}$ \\
\hline Imazethapyr & $22,6 \mathrm{a}$ & 2,24 a & $6,77 a b$ \\
\hline Chlorimuron & 22,4 a & 2,13 a & $6,58 \mathrm{~b}$ \\
\hline Metsulfuron & 22,6 a & $2,17 \mathrm{a}$ & 7,11 a \\
\hline \multicolumn{4}{|l|}{ Doses ${ }^{* *}$} \\
\hline Meia-dose & 22,7 a & $2,24 \mathrm{a}$ & $6,86 \mathrm{a}$ \\
\hline Dose-plena & 22,3 a & 2,17 a & $6,73 \mathrm{a}$ \\
\hline \multicolumn{4}{|l|}{ Épocas de aplicação } \\
\hline Florescimento & 22,4 a & $2,17 \mathrm{a}$ & $6,67 \mathrm{a}$ \\
\hline Enchimento de grãos & 22,7 a & 2,24 a & 6,91 a \\
\hline $\mathrm{CV}(\%)$ & 18,4 & 22,8 & 7,2 \\
\hline
\end{tabular}

- Médias comparadas dentro de cada fator, nas colunas, seguidas de mesma letra, năo diferem entre si pelo teste de Duncan ao nível de $1 \%$ de probabilidade.

** Correspondente à metade da dose usual $\mathrm{e}$ à dose recomendada, respectivamente.

TABELA 3 - Matéria seca da parte aérea de plântulas de Datura stramonium oriundas de plantas-mãe aspergidas com herbicidas na fase reprodutiva. Porto Alegre, RS, 1991.

\begin{tabular}{l|l|c|c|c}
\hline \multicolumn{1}{c|}{ Tratamentos } & \multicolumn{4}{c}{ Matéria seca (mg/plântula) } \\
\hline $\begin{array}{c}\text { Herbicida/dose/época } \\
\text { (g/ha) }\end{array}$ & Folhas & Cotilédones & Caule & Total \\
\hline $\begin{array}{l}\text { Metsulfuron/1,2/flor. }{ }^{1} \\
\text { Metsulfuron/2,4/flor. }\end{array}$ & $74,7 \mathrm{NS}$ & $5,58 \mathrm{NS}$ & $51,6 \mathrm{NS}$ & $131,9 \mathrm{NS}$ \\
Metsulfuron/1,2/ench. ${ }^{2}$ & $70,4 \mathrm{NS}$ & $7,00 \mathrm{NS}$ & $37,9 \mathrm{NS}$ & $115,3 \mathrm{NS}$ \\
Metsulfuron/2,4/ench. & $68,8 \mathrm{NS}$ & $8,18 \mathrm{NS}$ & $35,9 \mathrm{NS}$ & $112,8 \mathrm{NS}$ \\
Chlorimuron/30/flor. & $76,6 \mathrm{NS}$ & $8,13 \mathrm{NS}$ & $44,7 \mathrm{NS}$ & $129,4 \mathrm{NS}$ \\
Chlorimuron/60/flor. & $62,5 * *$ & $38,7 \mathrm{NS}$ & $106,3 * *$ \\
Chlorimuron/30/ench. & $70,5 \mathrm{NS}$ & $57,7 * *$ & $39,0 \mathrm{NS}$ & $117,6^{* *}$ \\
Chlorimuron/60/ench. & $71,3 \mathrm{NS}$ & $8,06 \mathrm{NS}$ & $30,9 * *$ & $99,0^{* *}$ \\
Imazaquin/ 75/flor. & $78,6 \mathrm{NS}$ & $10,45 \mathrm{NS}$ & $42,6 \mathrm{NS}$ & $121,4 \mathrm{NS}$ \\
Imazaquin/150/flor. & $77,8 \mathrm{NS}$ & $7,60 \mathrm{NS}$ & $41,4 \mathrm{NS}$ & $128,3 \mathrm{NS}$ \\
Imazaquin/ 75/ench. & $71,6 \mathrm{NS}$ & $8,33 \mathrm{NS}$ & $33,0 \mathrm{NS}$ & $116,3 * *$ \\
Imazaquin/150/ench. & $72,8 \mathrm{NS}$ & $5,50 \mathrm{NS}$ & $40,4 \mathrm{NS}$ & $119,6 \mathrm{NS}$ \\
Imazethapyr/ 50/flor. & $66,3 * *$ & $10,78 \mathrm{NS}$ & $42,6 \mathrm{NS}$ & $126,2 \mathrm{NS}$ \\
Imazethapyr/100/flor. & $67,7 * *$ & $9,30 \mathrm{NS}$ & $43,0 \mathrm{NS}$ & $118,6 * *$ \\
Imazethapyr/ 50/ench. & $79,0 \mathrm{NS}$ & $11,60 \mathrm{NS}$ & $34,4 \mathrm{NS}$ & $113,7 * *$ \\
Imazethapyr/100/ench. & $78,2 \mathrm{NS}$ & $6,75 \mathrm{NS}$ & $39,3 \mathrm{NS}$ & $125,0 \mathrm{NS}$ \\
Testemunha & 91,9 & $7,50 \mathrm{NS}$ & $42,4 \mathrm{NS}$ & $128,1 \mathrm{NS}$ \\
\hline CV (\%) & 12,4 & 10,88 & 53,0 & 155,8 \\
\hline
\end{tabular}

1 Florescimento.

2 Enchimento de gräos.

NS Médias comparadas com a testemunha nas colunas, não diferem significativamente pelo teste bilateral de Dunnet, ao nível de $1 \%$ de probabilidade.

** Médias comparadas com a testemunha nas colunas, diferem significativamente pelo teste bilateral de Dunnet, ao nível de $1 \%$ de probabilidade. 
menos produtos assimilados podem se translocar para as sementes.

Neste trabalho a redução de matéria seca das plântulas de quinquilho da geração seguinte pode ser atribuída ao acúmulo de herbicida em órgãos de reservas nas sementes ou à má formação das mesmas quando ainda se encontravam em desenvolvimento na planta-mãe.

No caso de balãozinho, a matéria seca das plântulas no estádio de duas folhas definitivas (Tabela 4) apresentou redução em relação à testemunha quando metsulfuron foi aspergido no florescimento a meia-dose. Já nos demais tratamentos herbicidas não se constataram diferenças em relação à testemunha. $\mathrm{O}$ mesmo pode-se afirmar das plântulas com quatro folhas definitivas (Tabela 4). Neste caso, o coeficiente de variação foi maior, impedindo verificação de diferenças ou então já ocorrera recuperação das plântulas. Na comparação isolada entre fatores, tais como herbicidas, doses e épocas de aplicação, não foi constatada diferença significativa entre os dois momentos de crescimento (Tabela 5).

A estatura das plântulas de balãozinho foi afetada pelos herbicidas. No estádio de duas folhas definitivas constatou-se que as aplicações de metsulfuron a meia-dose e de chlorimuron em ambas as doses, durante o florescimento, reduziram tal característica em 22, 16 e 23\%, respectivamente. Nas aspersões efetuadas no enchimento de grãos imazethapyr na dose-plena proporcionou redução da variável em $21 \%$ em relação à testemunha. Na avaliação das plântulas de balãozinho no estádio de quatro folhas definitivas, constatou-se a redução de sua estatura em relação à testemunha quando ocorreu aspersão dos seguintes compostos: metsulfuron e imazethapyr a meia-dose e chlorimuron e imazaquin a dose-plena, todos durante o florescimento; e chlorimuron e imazethapyr a dose-plena durante o enchimento de grãos (Tabela 4). Quanto à estatura de balãozinho, o coeficiente de variação das plântulas com quatro folhas definitivas foi aproxima damente o dob ro do obtido em plântulas com duas folhas (Tabelas 4 e 5). Pulverizações de chlorimuron e metsulfuron foram mais eficientes que de imazethapyr em relação à estatura de balãozinho. Já imazethapyr permaneceu em posição intermediária. Nas demais comparações isoladas entre doses e épocas de aplicação não houve diferenças significativas (Tabela 5).

A análise estatística dos dados da área foliar das plântulas de corriola não detectou diferenças entre tratamentos

TABELA 4 - Matéria seca e estatura da parte aérea de plântulas de Cardiospermum halicacabum oriundas de plantasmảe aspergidas com herbicidas na fase reprodutiva. Porto Alegre, RS, 1991/92.

\begin{tabular}{|c|c|c|c|c|}
\hline \multirow{2}{*}{$\begin{array}{c}\text { Tratamentos } \\
\begin{array}{c}\text { Herbicida/dose/época } \\
(\mathbf{g} / \mathbf{h a})\end{array}\end{array}$} & \multicolumn{2}{|c|}{ Matéria seca (mg/plântula) } & \multicolumn{2}{|c|}{ Estatura (cm) } \\
\hline & 2 folhas $^{\mathrm{a}}$ & 4 folhas $^{b}$ & 2 folhas & 4 folhas \\
\hline Metsulfuron $/ 1,2 /$ flor. $^{1}$ & $6,0^{* *}$ & $24,5 \mathrm{NS}$ & $3,20 * *$ & $5,00 * *$ \\
\hline Metsulfuron/2,4/flor. & $14,7 \mathrm{NS}$ & $30,5 \mathrm{NS}$ & $3,88 \mathrm{NS}$ & $5,54 \mathrm{NS}$ \\
\hline Metsulfuron/1,2/ench. ${ }^{2}$ & $9,3 \mathrm{NS}$ & $43,3 \mathrm{NS}$ & $3,70 \mathrm{NS}$ & $6,68 \mathrm{NS}$ \\
\hline Metsulfuron/2,4/ench. & $12,5 \mathrm{NS}$ & $28,3 \mathrm{NS}$ & $3,89 \mathrm{NS}$ & $5,49 \mathrm{NS}$ \\
\hline Chlorimuron/30/flor. & $10,5 \mathrm{NS}$ & $37,0 \mathrm{NS}$ & $3,45 * *$ & $5,88^{* *}$ \\
\hline Chlorimuron/60/flor. & $9,0 \mathrm{NS}$ & $29,0 \mathrm{NS}$ & $3,15^{* *}$ & $5,23 * *$ \\
\hline Chlorimuron/30/ench. & $15,3 \mathrm{NS}$ & $34,8 \mathrm{NS}$ & $4,09 \mathrm{NS}$ & 6,04 NS \\
\hline Chlorimuron/60/ench. & $16,5 \mathrm{NS}$ & $20,8 \mathrm{NS}$ & $3,92 \mathrm{NS}$ & $4,75 * *$ \\
\hline Imazaquin/ 75/flor. & $10,5 \mathrm{NS}$ & $31,0 \mathrm{NS}$ & $4,13 \mathrm{NS}$ & $6,20 \mathrm{NS}$ \\
\hline Imazaquin/150/flor. & $13,8 \mathrm{NS}$ & $31,0 \mathrm{NS}$ & $3,86 \mathrm{NS}$ & $5,15 * *$ \\
\hline Imazaquin/ 75/ench. & $12,5 \mathrm{NS}$ & $27,3 \mathrm{NS}$ & $3,48 \mathrm{NS}$ & $5,45 \mathrm{NS}$ \\
\hline Imazaquin/150/ench. & $12,5 \mathrm{NS}$ & $38,3 \mathrm{NS}$ & $3,88 \mathrm{NS}$ & $5,55 \mathrm{NS}$ \\
\hline Imazethapyr/ 50/flor. & $12,0 \mathrm{NS}$ & $20,0 \mathrm{NS}$ & $4,07 \mathrm{NS}$ & $4,58 * *$ \\
\hline Imazethapyr/100/flor. & $13,0 \mathrm{NS}$ & $28,0 \mathrm{NS}$ & $3,91 \mathrm{NS}$ & $5,60 \mathrm{NS}$ \\
\hline Imazethapyr/ 50/flor. & $13,7 \mathrm{NS}$ & $34,3 \mathrm{NS}$ & $4,34 \mathrm{NS}$ & $5,52 \mathrm{NS}$ \\
\hline Imazethapyr/100/flor. & $9,0 \mathrm{NS}$ & $22,7 \mathrm{NS}$ & $3,25 * *$ & $4,79 * *$ \\
\hline Testemunha & 16,0 & 40,5 & 4,10 & 7,24 \\
\hline $\mathrm{CV}(\%)$ & 22,49 & 26,51 & 6,31 & 13,01 \\
\hline
\end{tabular}

1 Florescimento

2 Enchimento de grấos

* Matéria seca e estatura das plântulas com 2 folhas definitivas.

b Matéria seca e estatura das plântulas com 4 folhas definitivas.

NS Médias comparadas com a testemunha nas colunas, năo diferem significativamente pelo teste bilateral de Dunnet, ao nível de $1 \%$ de probabilidade.

** Médias comparadas com a testemunha nas colunas, diferem significativamente pelo teste bilateral de Dunnet ao nível de $1 \%$ de probabilidade. 
TABELA 5 - Matéria seca da parte aérea e estatura de plântulas de Cardiospermum halicacabum em função da aplicaçäo de herbicidas na fase reprodutiva. Porto Alegre, RS, 1991/92.

\begin{tabular}{|c|c|c|c|c|}
\hline \multirow{3}{*}{$\begin{array}{c}\text { Tratamentos } \\
\text { Fatores e níveis }\end{array}$} & \multicolumn{4}{|c|}{ Características } \\
\hline & \multicolumn{2}{|c|}{ Matéria seca (mg/plântula) ${ }^{\mathbf{a}}$} & \multicolumn{2}{|c|}{ Estatura (cm) ${ }^{\mathbf{b}}$} \\
\hline & 2 folhas & 4 folhas & 2 folhas & 4 folhas \\
\hline \multicolumn{5}{|l|}{ Herbicidas } \\
\hline Imazaquin & $12,3 \mathrm{a}^{*}$ & 31,9 a & $3,84 \mathrm{ab}$ & 5,59 a \\
\hline Imazethapyr & 11,9 a & 26,3 a & 3,89 a & 5,12 a \\
\hline Chlorimuron & 12,8 a & 30,4 a & $3,65 \mathrm{~b}$ & 5,47 a \\
\hline Metsulfuron & 10,6 a & 31,6 a & $3,67 \mathrm{~b}$ & 5,68 a \\
\hline \multicolumn{5}{|l|}{ Doses"* } \\
\hline Meia-dose & $11,2 \mathrm{a}$ & $31,5 \mathrm{a}$ & 3,81 a & 5,67 a \\
\hline Dose-plena & 12,6 a & 28,6 a & 3,72 a & 5,26 a \\
\hline \multicolumn{5}{|l|}{ Épocas de aplicação } \\
\hline Florescimento & 11,2 a & 28,9 a & 3,71 a & 5,40 a \\
\hline Enchimento de grấos & $12,7 \mathrm{a}$ & 31,2 a & 3,82 a & 5,53 a \\
\hline CV $(\%)$ & 23,4 & 27,78 & 6,43 & 13,76 \\
\hline
\end{tabular}

- Médias comparadas dentro de cada fator, nas colunas, seguidas de mesma letra, năo diferem significativamente entre si pelo teste de Duncan, ao nível de $1 \%$ de probabilidade.

- Plântulas com 2 e 4 folhas definitivas, respectivamente.

b Pläntulas com 2 e 4 folhas definitivas, respectivamente.

** Correspondentes à metade da dose usual $\mathbf{e}$ à dose recomendada, respectivamente.

herbicidas e testemunha e tampouco na comparação isolada entre os fatores. Quanto a estatura e matéria seca de caule e folhas das plântulas de corriola, a análise mostrou comportamento similar entre testemunha e tratamentos herbicidas. De igual forma, na comparação entre compostos, doses e épocas de aplicação não se verificaram diferenças significativas (Tabela 6). Também em relação a matéria seca total da parte aérea de plântulas de corriola não foram observadas diferenças entre testemunha e tratamentos herbicidas. O mesmo ocorreu na comparação entre os fatores (Tabela 6).

Alguns dos resultados encontrados confirmam a hipótese inicial de que certos herbicidas, ao serem aspergidos durante a fase reprodutiva de plantas daninhas, podem afetar o desenvolvimento inicial das plântulas subseqüentes, promovendo modificações na matéria seca e na estatura das mesmas, como ocorreu em algumas situações para quinquilho, balãozinho e corriola.

Considera-se a possibilidade de redução na distribuição de assimilados para as sementes, o que impossibilitou às plantas deslocar quantidades suficientes para suprir suas necessidades e formar sementes íntegras.

Uma das dificuldades para recomendar a aspersão de herbicidas na fase reprodutiva de plantas daninhas, com a finalidade de impedir a formação de sementes íntegras está na heterogeneidade de desenvolvimento dentro de uma mesma planta (Gutterman, 1985). Isto deve-se ao fato de que numa mesma planta encontram-se, simultâneamente, botões florais, flores e frutos em vários estádios. Assim, a escolha do momento correto de aplicação, de modo a obter o efeito desejável, nem sempre coincide com o mais propício.
Outro ponto negativo a destacar é que a sensibilidade das plantas daninhas aos herbicidas decresce à medida que as mesmas se desenvolvem (Gressel, 1985). Como as aplicações neste trabalho foram realizadas na fase de plantas adultas, ocasião em que folhas e ramos atingiram o máximo desenvolvimento de características, como espessura cuticular e pilosidade da superfície foliar, tais propriedades podem dificultar a absorção dos herbicidas (Esau, 1974; Garcia Torres \& Fernandez-Quintanilla, 1991). Cabe ressaltar ainda que grande parte das sementes testadas em laboratório e em casa-de-vegetação pode ter escapado dos efeitos herbicidas maiores, os quais podem ter se mostrado ativos apenas sobre sementes recém-formadas na ocasião de sua aplicação.

As constatações verificadas assemelham-se aos dados encontrados por Ratnayake \& Shaw (1992), que referiram redução na emergência de plântulas normais de Cassia obtusifolia L., quando plantas-mãe foram aspergidas pela imidazolinona AC 263.222, no início do desenvolvimento das sementes. As causas seriam conseqüência da inibição da enzima ALS envolvida na síntese dos aminoácidos valina, leucina e isoleucina (Shaner et al., 1984). Estes aminoácidos são importantes na síntese de proteínas específicas nas sementes, e seus efeitos neste processo podem resultar em anormalidades de plântulas oriundas desta aplicação. Este indício corrobora a idéia de que houve má formação das sementes ainda na planta-mãe e não acúmulo de moléculas herbicidas nas sementes.

No entanto, Fawcet \& Slife (1978) encontraram resultados distintos. Citam os autores que a redução na matéria seca das plântulas pode ser devido ao baixo acúmulo de 
TABELA 6 - Estatura e matéria seca da parte aérea de plântulas de Ipomoea grandifolia oriundas de plantas-mãe aspergidas com herbicidas na fase reprodutiva. Porto Alegre, RS, 1991/92.

\begin{tabular}{|c|c|c|c|c|}
\hline \multirow{3}{*}{$\begin{array}{c}\text { Tratamentos } \\
\text { Fatores e níveis }\end{array}$} & \multicolumn{4}{|c|}{ Características } \\
\hline & \multirow{2}{*}{$\begin{array}{l}\text { Estatura } \\
\text { de plântula }\end{array}$} & \multicolumn{3}{|c|}{ Matéria seca (mg/plântula) } \\
\hline & & Caule & Folhas & Total \\
\hline \multicolumn{5}{|l|}{ Herbicidas } \\
\hline Imazaquin & $9,25 \mathrm{a}^{*}$ & 42,04 a & $43,58 \mathrm{a}$ & 85,79 a \\
\hline Imazethapyr & $10,50 \mathrm{a}$ & 42,91 a & $46,90 \mathrm{a}$ & 90,79 a \\
\hline Clorimuron & 9,59 a & 37,49 a & 39,02 a & 76,51 a \\
\hline Metsulfuron & 9,63 a & 42,03 a & 46,25 a & 75,11 a \\
\hline \multicolumn{5}{|l|}{ Doses ${ }^{* *}$} \\
\hline Meia-dose & 9,56 a & 40,96 a & 43,43 a & 84,39 a \\
\hline Dose-plena & 9,56 a & 41,28 a & 38,53 a & 79,71 a \\
\hline \multicolumn{5}{|l|}{ Épocas de aplicação } \\
\hline Florescimento & 9,64 a & 40,72 a & 44,27 a & 85,01 a \\
\hline Enchimento de grãos & 9,85 a & 41,52 a & 37,53 a & 79,08 a \\
\hline $\mathrm{CV}(\%)$ & 23,25 & 20,12 & 24,35 & 20,48 \\
\hline
\end{tabular}

* Médias comparadas dentro de cada fator, nas colunas, seguidas de mesma letra, năo diferem significativamente entre si pelo teste de Duncan, ao nível de $1 \%$ de probabilidade.

* Correspondentes à metade da dose usual e à dose recomendada, respectivamente.

reservas nas sementes, aliado a presença de moléculas herbicidas quando de sua formação na planta-mãe, o que proporcionaria reduzido crescimento inicial. Estes pesquisadores obtiveram sintomas de dano por 2,4-D em plântulas de quinquilho oriundas de sementes cujas plantas-mãe foram aspergidas durante o enchimento de grãos, demonstrando então que o herbicida pode ter sido translocado e armazenado durante o desenvolvimento das sementes.

Os dados encontrados nestes experimentos sugerem que, embora os herbicidas testados, de um modo geral não atuassem diretamente na viabilidade das sementes geradas por plantas tratadas, ainda assim eles podem interferir no desenvolvimento inicial das plântulas originadas. Considerando que o desenvolvimento inicial das plantas daninhas seja prejudicado, produzindo plantas anormais ou pouco vigorosas, provavelmente estas mostrarão menor capacidade competitiva com a cultura subseqüente, o que fatalmente reduziria o seu sucesso competitivo.

A utilização de herbicidas em estádios mais avançados de plantas daninhas, a fim de evitar o reabastecimento do banco de sementes em áreas previamente pouco infestadas com espécies consideradas nocivas, deve ser considerada como mais uma possibilidade promissora do manejo de plantas daninhas. Esta investigação demonstra que aplicações herbicidas realizadas durante o florescimento de espécies daninhas, podem levar as plantas-mãe a produzirem sementes que dêem origem a plântulas menos vigorosas. Em conseqüência, estas podem mostrar maior suscetibilidade aos métodos mecânico ou químico de controle comumente adotados para sua eliminação, ou mesmo apresentar maior suscetibilidade às medidas culturais recomendadas para reduzir sua interferência.

\section{LITERATURA CITADA}

ANDERSEN,R.N.; HELGESON, E.A. Control of wild oats by prevention of normal seed development with sodium 2,2- dichloropropionate. Weeds, Champaign, v.6, p.263-270, 1958.

BEYER, E.M.; DUFFY, M.J.; HAY, J.V.; SCHLUETER, D. D. Sulfonylurea. In: KEARNEY, P.C.; KAUFMAN, D.D. (eds). Herbicides: chemistry, degradation, and mode of action. New York: M. Dekker. 1988. v.3, p.117-189.

CARMONA, R. Problemática e manejo de bancos de sementes de invasoras em solos agrícolas. Planta Daninha, Brasilia, v.10, n.1-2, p.5-16, 1992.

CLAUS, J.S. Chlorimuron-ethyl (Classic): A new broadleaf postemergence herbicide in soybean. Weed Technology, Champaign, v.1, p.114-115, 1987.

CONGLETON, W.F.; V ANCANTFORT, A.M.; LIGNOWSKI, E.M. Imazaquin (Scepter): a new soybean herbicide. Weed Technology, Champaign, v.1, p.186-188, 1987.

ESAU, K. Anatomia de plantas corn sementes. 9 ed. São Paulo: Blucher, 1974. 203p.

EVANS, R.A.; KAY, B.L.; McKELL, C. Herbicides to prevent seed set on germination of medusahead. Weeds, Champaign, v.11, p.270-273, 1963.

FAWCET, R.S.; SLIFE, F.W. Effects of 2,4-D and dalapon on weed seed production and dormancy. Weed Science, Champaign, v.26, p.543-547, 1978. 
FENTON, R.; JUTSUN, A. Herbicide-resistant weeds: developing our defenses. Shell Agriculture, Rudwick, v.11, p.22-28, 1991.

GARCIA TORRES, L.; FERNANDEZ-QUINTANILLA, C. Fundamentos sobre malas hierbas y herbicidas. Madri: Multi-Prensa, 1991. 348p.

GRESSEL, J. Herbicide tolerance and resistance: alteration of site activity. In: DUKE, S.O., (ed). Weed physiology. Boca Raton: CRC Press, 1985. v.2, p.159-190.

GUTTERMAN, Y. Flowering, seed development, and the influences during seed maturation on seed germination of annual weeds. In: DUKE, S.O., (ed). Weed physiology. Boca Raton: CRC Press, v.1, p.1-26, 1985.

HENRY, W.T.; BAUMAN, T.T. Interference between soybean (Glycine max) and jimsonweed (Datura stramonium) in Indiana. Weed Technology, Champaign, v.5, p.759-764, 1991.

HILL, E.R.; LAGHMAN, W.H.; MAYNARD, D.N. Translocation of amitrole in yellow nutsedge and its effect on seed germination. Weeds, Champaign, v.11, p.165166, 1963.

IS AACS, M.A.; MURD OCK, E.C.; TOLER, J.E.; WALLACE, S.U. Effects of late-season herbicide applications on sicklepod (Cassia obtusifolia) seed production and viability. Weed Science, Champaign, v.37, p.761-765, 1989.

JOHNSTON, S.K.; MURRAY, D.S.; WILLIAMS, J.C. Germination and emergence of balloonvine (Cardiospermum halicacabum). Weed Science, Champaign, v.27, p.73-76, 1979.

LEVITT, J.; LOVETT, J.V. Activity of allelochemichals of Datura stramonium L. (thorn-apple) in contrasting soil types. Plant and Soil, v.79, p.181-189, 1984.
LORENZI, H. Plantas daninhas do Brasil; terrestres, aquáticas, parasitas, tóxicas e medicinais. 2. ed. Nova Odessa: Plantarum, 1991. 440p.

MITICH, L.W. Jimsonweed (Datura stramonium L.). Weed Technology, Champaign, v3, p.208-210, 1989.

PAWLAK, J.A.; MURRAY, D.S.; SMITH, B.S. Influence of capsule age on germination of nondormant Datura stramonium seed. Weed Technology, Champaign, v.4, p.31-34, 1990.

RAY, T.B. Site of action of chlorsulfuron. Plant Physiology, Lancaster, v.75, p.827-831, 1984.

RATNAYAKE, S.; SHAW, D.R. Effects of harvest-aid herbicides on soybean (Glycine max) seed yield and quality. Weed Technology, Champaign, v.6, p.339-344, 1992.

ROJAS-GARCIDUENAS, M.; KOMMEDAHL, T. The effects of 2,4-D on germination of pigweed seeds. Weeds, Champaign, v.8, p.1-5, 1960.

SHANER, D.L.; ANDERSON, P.C.; STIDHAM, M.A. Inndazolinones: Potent inhibitors of acetohydroxyacid synthase. Plant Physiology, Lancaster, v.76, p.545546, 1984.

TAYLORSON, R.B. The role of seed dormancy and germination in devising weed control methods. In: CONFERÊNCIA MUNDIAL DE INVESTIGACION EN SOYA, 4, Buenos Aires. Actas. Buenos Aires: J.A. PASCALE, 1989. p.1097-1104.

WEAVER, S.O.; WARWICK, S.I. The biology of canadian weeds. 64. Datura stramonium L. Canadian Journal Plant Science, Ontario, v.64, p.979-991, 1984. 